\title{
Antimicrobial Activities of Mucuna pruriens (Agbara) on Some Human Pathogens
}

\author{
Mbajiuka Chinedu Stanley ${ }^{1}$, Obeagu Emmanuel Ifeanyi ${ }^{2 *}$, Ochei Kingsley \\ Chinedum $^{3}$, Ifediora Afoma Chinwe ${ }^{2}$, Okezie Emmanuel ${ }^{1}$ and Odo Nkechinyelu \\ Nwamaka $^{4}$ \\ 1.Department of Microbiology,Michael Okpara University of Agriculture,Umudike,Abia State,Nigeria. \\ 2.Diagnostic Laboratory Unit,University Health Services Department, Michael Okpara University of \\ Agriculture, Umudike,Abia State, Nigeria. \\ 3.Department of H.S.S. and Laboratory, FHI 360 Country Office, Plot 1073-A1 Garki, Abuja, FCT, Nigeria. \\ 4Department of Applied Microbiology, Ebonyi State University, Abakaliki, Nigeria.
}

\begin{abstract}
Increasing rate of development of resistance to commonly used antibiotics have led to serach for newer,more effective, affordable and easily available drugs.In this study, the organic and aqueous extracts of Mucuna pruriens seeds were obtained using a Soxhlet extractor.The antimicrobial activities of the extracts were tested on some human pathogens namely Escherichia coli, Staphylococcus aureus, and Candida albicans, using $0.3 \mathrm{~g} / \mathrm{ml}$ concentration $n d$ the standard method of agar disc diffusion assay.Results obtained showed that the extract have highest inhibitory effect on the gram positive S.aureus, lowereffect on the gram negative E.coli and no inhibtion on the fungi(C.albicans). Acetone extract produced the highest zone of inhibition 97mm), followed by ethanol $(6 \mathrm{~mm})$, and water $(4 \mathrm{~mm})$ extract respectively.Minimum inhibitory concentration assay of 0.0125 and $0.025 \mathrm{~g} / \mathrm{ml}$ for the organic extracts, and 0.025 and $0.05 \mathrm{~g} / \mathrm{ml}$ for the aqueous extracts on S.aureus and E.coli, respectively. The study proved that Mucuna pruriens seeds, apart from their roles as food addictives and supplements, can also be utilized as effective and cheap source of antimicrobial agent.
\end{abstract}

Keywords: Antimicrobial activities of Mucuna pruriens, some human pathogens, minimum inhibitory concentration and zone of inhibition.

\section{Introduction}

Medicinal plants have been used for centuries as remedies for human diseases, and offer new sources of biologically active chemical compounds as antimicrobial agents(Das et al.,2010). There has been growing interest in the investigation of the alternative route for the substitution of synthetic chemicals,side effects of which are always in question(Yerra et al.,2005).For this reason,the essentaial oils and the extracts of many plants have been prepared and screened for their antimicrobial activities,leading to accumulation of large number of reports in the literature concerning these properties(Salau and Odeleye,2007).

Out of several hundred thousnad medicinal plant species around the globe,only a small portion has beeen investigated both phytochemically and pharmacologically(Hostettmann,1999).It has been estimated that 14-28\% Of higher plants derived components were discovered after following up aon ethno-medical use of plants(Neube et al.,2008).

The side effects and the resistance that pathogenic microorganisms build against antibiotics has been given rise to a growing interste in the investigation of biologically active compounds from plants for the discovery of new antimicrobial agents(Yerra et al.,2005). Resistance to penicillin by S.areus was first reported in 1942 , and by 1960 ,more than $80 \%$ of both community and hospital acquired taphylococcal isolates were resistant to penicillin(Lowyi,2003). The development of resistance to the newest antibiotics by the microorganisms causing most of the infectious diseases with delibitating effects made the case worse(Adekunle and Adekunle,2009).

Recently,the acceptance of traditional medicine as an alternative form of healthcare and the development of microbial resistance to available antibiotics has led the researchers to investigate the antimicrobial activity of medicinal plants(Adekunle and Adekunle,2009). Another driving factor for the renewed interest in plant antimicrobials in the past 20 years has been the rapid rate of plant species extinction(Lewis et al.,1995), as there is a feeling among natural products-chemists and microbiologists alike that the multitude of potentially useful phytochemical strucures which be synthesized chemically is at risk of being lost irrtrieably(Borris, 1996).

Antimicrobials of plant origin have enermous therapeutic potential.They are effective in the treatment of infectious disease while simultaneously mitigating many of the side effects often associated with synthetic antimicrobials(Iwu et al.,1999). 
In Kenya about 400 plant species have been recorded to be used in traditional remedies(Kokwaro,1976).In the rural areas, even when western health facilities are available,traditional medicine is viewed as an efficient and accepatable sysytem from a cultural perspective(Munguti,1997) and as a result,traditional medicine usually exists side by side with western forms of healthcare(Sindga,1994).Generally in developing countries, where bactrerial infections are prevalent due to inadequate sanitation,poor hygiene and overcrowded conditions.It is estimated that about $80 \%$ of the population rely on traditional medicine for their primary health care.There arises a need therefore to screen medicinal plants for bioactive compounds as a basis for further pharmacological studies(Esther and Johannes,2003).

Although therre are other approaches to selecting plants species for biological investigation,selecting species that are used in traditional medicine is reported to be more valuable, and many drugs that are of plant origin were discovered from plants used in traditional medicine(Cotton,1996).

\section{AIMS AND OBJECTIVES OF THE STUDY}

The incidence and increasing frequency of micrioorganisms that are resistant to common and generally accepted effective first choice drugs is on the increase. As this resistivity increases the need for newre and/or alternative therapy becomes necesssary(Adekunle and Adekunle,2009).This study was designed to asses potentials of the aqueous extracts and organic(ethanol and acetone) extracts of mucuna pruriens seeds on some human pathogens.

$\begin{array}{ll}\text {-Gram negative } & \text {-Escherichia coli(Enterobacteriacae) } \\ \text {-Gram postive } & \text {-Staphylococcus areus(staphylococcaceae) } \\ \text {-Fungi } & \text {-Candiad albicans(Ascomycota) }\end{array}$

\section{Materials Method}

SOURCE OF PLANT AND IDENTIFICATION

The seeds ofMucuna pruriens were collected and identified at the National Root Croop Research Institute,Umudike.

\section{SOURCE OF MICROORGANISMS AND IDENTIFICATION}

The microorganisms s.areus,E.coli and C.albicans were obtained from the stock culture of Federal Medical Centre,Umuahia,Abia State,Nigeria.

\section{PREPARATION OF CRUDE EXTRACTS OF THE PLANT MATERIAL}

Extraction methods involve separation of medicinal active functions of plant tissue from inactive/inert components, by using selective solvents and extraction technology.Solvents diffuse into solid plant tissues and solubilize compounds of similar polarity.Quality of plant extract depends on plant material,choice of solvents and the extraction(Das et al.,2010).

The extraction method that has been widely used by researchers is plant tissue homogenization in solvent(Basri and Fan,2005).

\section{AQUEOUS EXTRACTION}

The seeds were dried in shade, and powdered in a mechanical grinder to a fine paste of uniform consisitency(Yerra et al.,2005).

$100 \mathrm{~g}$ of the powder was soaked in $750 \mathrm{ml}$ of distilled water and allowed to stand for $24 \mathrm{hr}$ (Aguiyi et al.1996).

\section{ORGANIC EXTRACTION}

$100 \mathrm{~g}$ of the powdered seed was soaked in $750 \mathrm{ml}$ of ethanol and acetone respectively,for $72 \mathrm{hr}$, and extracted using a soxhlet extractor at a temperature not exceeding the boiling point of the solvent(Kianbakht and Jahaniani,2003). The extracts were filtered using whitman filter paper(No.1) and then concentrated in a vacuum and dried(Das et al.,2010).

\section{PREPARARTION OF MEDIA,DISC AND MICROORGANISMS}

Media:9.5g of mueller Hinton agar was weighed aseptically and dissolved in $250 \mathrm{ml}$ of distilled water(Mueller and Hinton,1941).The solution was sterilized by autoclaving at $121^{\circ} \mathrm{c} / 15 \mathrm{pa}$ for 15 minutes and allowed to cool to $45-50^{\circ} \mathrm{c} .20 \mathrm{ml}$ of the molten agar was poured intopetri-dishes and allowed to solidify(Das et al.,2010).

Discs:Discs were made from whatmann no 1 filter paper,using a $6 \mathrm{~mm}$ perforator.The discs were placed in a bottle and sterilized in a hot air oven at $60^{\circ} \mathrm{C}$ for 10 mins.

Microorganisms:Solutions of the microorganisms were made,using peptone water,and standardized to the McFarland's O.D.turbidity standard.This gave a concentration of $10^{8}$ C.F.U $/ \mathrm{ml}$ of the microorganisms(Das et al.,2010). 


\section{STERILIZATION AND STERILITY TEST OF MATERIALS}

Sterilization:Media were sterilized by autoclaving at $121^{\circ} \mathrm{C} / 15 \mathrm{pa}$ for 15 minutes,followed by cooling to 45 $50^{\circ} \mathrm{C}$.

Glass wares such as petri-dishes,pipettes,test tubes, etc were sterilized by dry heat,using the hot air-oven set at $150 / 160^{\circ} \mathrm{C}$ for 2 hours.

\section{Sterility test}

Media:100ml of agar was prepared,autoclaved and allowed to cool to $45-50^{\circ} \mathrm{C} .20 \mathrm{ml}$ of the molten agar were poured into 3 sterile petri-dishes,allowed to solidify and then incubated at $37^{\circ} \mathrm{C}$ for 72 hours. No growth on the medium after incubation indicated sterility of both the media and the petri-dishes.

Solutions like distilled water were plated on sterile petri-dishes and incubated at $37^{\circ} \mathrm{C}$ for 24 hours. No growth indicated sterility.

\section{ANTIMICROBIAL SCREENING OF PLANTS EXTRACTS}

Antimicrobial activity was measured using the standard method of agar disc diffusion assay.This method has been widely used to assay plant extract for antimicrobial activity(Eugene et al.,2006).

In this method,6mm sterilized filter paper discs(whatman no1) are saturated with filter sterilized plant extract of desired concentration(Salie et al.,1996). The impregnated discs are then placed on to the surface of a suitable solid agar medium such as Mueller and Hinton(Das et al.,2010), trypton soy agar(Lourens et al.,2004), or Nutrient agar(Doughari,2006).The medium has been pre-incubated with test organisms standardized to inoculum size $1 * 10^{8}$ C.F.U/ml of bacteria, which is equal to McFarland 0.5 turbidity standard(Baris et al.,2006). $0 . \mathrm{ml}$ of standardized inoculums size of each test organism924hr old), was spread on agar plate surfaces.Paper discs were impregnanted in $0.3 \mathrm{~g} / \mathrm{ml}$ of the plant extract(Yerra et al.,2005).The impregnanted discs were placed on the medium,suitably spaced,with a disc of gentamicin as positive control.The plates were then incubated at $5^{\circ} \mathrm{C}$ for 1 hour to permit good diffusion(Das et al.,2010), and then incubated for 24 hours at $37^{\circ} \mathrm{C}($ bacteria) and 48 hours at $25^{\circ} \mathrm{C}$ (fungi),(Baris et al.,2006). After incubation,diameter of zone of inhibiton was measured to the nearest whole millimeter,at the point wherein there is a prominent reduction of $80 \%$ growth(Salie et al.,1996).

\section{DETERMINATION OF MINIMUM INHIBITORY CONCENTRATION(MIC) AND MINIMUM BACTERICIDAL CONCENTRATION(MBC)}

M.I.C:This is the lowest concentration of antimicrobials that will inhibit the visible growth of microorganisms after an overnight incubation(Das et al.,2010).

The metho employed is the broth macrodilution assay.Here is a set of test tubes with different concentrations of plant extract,with equal volumes are prepared.The tubes are inoculated with test microorganisms of standard concentration $\left(1 * 10^{8}\right.$ C.F.U/ml) and incubated at $37^{\circ} \mathrm{C}$ for 24 hours(Laurens et al.,2004).

After incubation,the tubes are examined for changes in turbidity as an indicator of growth. The first tube that appears clear is taen to be the MIC of the extract.

Indicators like tetrazolium salts or resazurin dye(Umeh et al.,2005), or spectrophotometry(Devienne and Raddi,2002), are used to determine presence of growth.

For spectrophotometric method,the absorbance is usually at $620 \mathrm{~nm}$ with negative control as blank(Salie et al.,1996).The lowest concentration which gives a zero absorbance.Reading is the MIC of the plants extract(Salie et al.,1996).

MBC:This is the lowest concentration of antimicrobials that will kill microorganisms after an overnight incubation.

From the MIC tubes, the tube after the MIC tube contains the minimal bactericidal concentration(Das et al.,2010).

\section{YIELD OF EXTRACT}

\section{Results}

Extracts mисипа pruriens seeds was extracted with a Soxhlet extractor using different solvents(acetone,ethanol,coldwater).Water gave the highest yield,followed byacetone and ethanol respectively,as shown in table111.The percentage yield is derived by dividing the yield gotten by the initial gram.Initial gram used was $100 \mathrm{~g}$ of the powdered seeds in $750 \mathrm{mls}$ ofsolvents.

\section{ANTIMICROBIAL SENSITIVITY ASSAY}

Antimicrobial sensitivity assay of the differnt extracts were carried out using the disc diffusion method against the isolates.The result gotten as shown in table ivindicates that acetone extract produced the highest 
inhibition, $7 \mathrm{~mm}$ followed by ethanol $6 \mathrm{~mm}$,and water 4 mmextract respectively.Also S.areus,showed greater sensitivity followed by E.coli,C.albicans showded no significant sensitivity to the extracts.

\section{MINIMUM INHIBOTORY CONCENTRATION}

M.I.C. of the organic and aqueous extracts were determined using the broth macrodilution assay method.Different concentrations $(0.1,0.05,0.025,0.0125,0.00625$, and $0.00313 \mathrm{~g} / \mathrm{ml})$ of the extract was tested against the different isolates.The results as shown in tabls $\mathrm{v}$ and vi indicates that the M.I.C. of the organic extracts was obtained at a concentration of 0.0125 and $0.025 \mathrm{~g} / \mathrm{ml}$ for S.aureus and E.coli respectively. While that of the aqueous was at 0.025 and $0.05 \mathrm{~g} / \mathrm{ml}$ for S.areus and E.coli respectively.

Tableiii:percentage yield of crude extracts of mucuna pruriens seeds

\begin{tabular}{llr} 
Solvent & Weightof yield & \%yield \\
\hline Cold water & $17.7 \mathrm{~g}$ & $17.7 \%$ \\
Acetone & $17.4 \mathrm{~g}$ & $17.4 \%$ \\
Ethanol & $7.8 \mathrm{~g}$ & $7.8 \%$ \\
\hline
\end{tabular}

Tableiv:Mean zone of inhibition( $\mathrm{mm}$ ) of crude extract using the disc diffusion method

\begin{tabular}{llcc} 
Solvent & C.albican & \multicolumn{2}{c}{ S.areus } \\
\hline Gentamycin & 7 & 9 & 8 coli \\
Acetone & - & 7 & 6 \\
Ethanol & - & 6 & 6 \\
Water & - & 5 & 4 \\
\hline
\end{tabular}

Table v:M.I.C. of organic extracts of Mucuna pruriens seeds for different isolates

\begin{tabular}{|c|c|c|c|c|c|c|c|}
\hline & & & Concel & tration & /ml) & & \\
\hline Organism & 0.1 & 0.05 & 0.025 & 0.0125 & 0.00625 & 0.00313 & MIC \\
\hline E.coli & + & + & + & - & - & - & 0.025 \\
\hline S.areus & + & + & + & + & - & - & 0.0125 \\
\hline C.albicans & - & - & - & - & - & - & - \\
\hline
\end{tabular}

Table vi : M.I.C.of extract of Mucuna pruriens seds for the different isolates

\begin{tabular}{|c|c|c|c|c|c|c|c|}
\hline \multirow[b]{2}{*}{ Organism } & \multicolumn{7}{|c|}{ Concentration $(\mathrm{g} / \mathrm{ml})$} \\
\hline & 0.1 & 0.05 & 0.025 & 0.0125 & 0.00625 & 0.00313 & MIC \\
\hline E.coli & + & + & - & - & - & - & 0.05 \\
\hline S.areus & + & + & + & + & - & - & 0.025 \\
\hline C.albicans & - & - & - & - & - & - & - \\
\hline
\end{tabular}

$+=$ Inhibition

-=No inhibition

\section{Discussion}

The phytochemical analysis of Mucuna pruriens has been reported to contain alkaloids,flavonoids,5hydroxyphoxytryptamine,saponins,etc.the principal constituents are LDihydroxyphenylamine(L-DOPA) and the bioactive alkaloids mucunine,mucunadine,pruienine, and nicotine as well as beta sitosterol,lecithin,oils,gallic acids,etc(Yerra et al.,2005).

In this study,aqueous and organic extracts of seeds of Mucuna pruriens were tested on the hospital isolates E.coli,S.areus and C.albicans,Results of the disc diffusion tests in table iv showed that acetone extract was more effective followed by ethanol and water extracts respectively.Also from the result,S.aureus showed greates senstivity to acetone,ethanol,and water in that order.E.coli showed lower sensitivity to the different extracts,while C.albicans showed no significant sensitivity to the extract.Prevoius report by Salau and Odeleye(2007) on antimicrobial activity of mucuma pruriens leaf against S.aureus,C.albicans etc indicated that the extract had activity on all tested microorganisms except C.albicans.A report by Yerra et al(2005) on antimicrobial activity of Mucuna pruriens seeds against S.aureus,E.coli,V.cholera,B.cerus, etc indicated positive action against all tested organisms with minimal action on S.aureus and none on $V$.cholera.Despite the similarities,the disparity in these reports compared to the findings in this study,may depend on the different materials and methods employed. 
Major plant pathogens to the gram negative bacteria(George et al.,2002), which makes the low activity of plant antimicrobials against this group of microorganisms puzzling. The results showed that Mucuna pruriens extracts have greater activity on Gram positive bacteria S.aureus, than on Gram negative bacteria e.coli, and no fungi C.albicans. Since most plant pathogens belong to the Gram negative bacteria,this shows that plants might have developed means of delivering their antimicrobials into bacterials cells.Both fungi and Gram negative bacteria have evolved permeability barriers(an outer membrane in Gram negative bacteria,and ergosterol in fungi),(George et al.,2002).By contrast,the single membrane of the Gram positive bacteria is considerably more accessible to permeation by amphipathic toxins.

The fact that extraction agents, acetone, ethanol,and water,produced no visible sign of any activity against the hospital isolates means that the extraction agents made no contributions to the antimicrobial potency of the plant extracts.Recently,Eloff(1998) examined a variety of extractants for their ability to solubilize antimicrobials from plants,rate of extraction,ease of removal,toxicity in bioassay, and acetone received the highest rating. This study on Mucuna pruriens has further established this facts.

Nutritional analysis reveal that Mucuna pruriens contains crude protein ranged from 20-29\%,crude lipid 6-7\% total dietary fibre $8-10 \%$, ash $3 \%$ and carbohydrates $50-60 \%$. Thus apart from its use as a food supplement,this study has proved thatMucuna pruriens can be used as an antimicrobial agent in the treatment of bacterial infections.Its ready availability locally and at cheap affordable prices will surely enhance their application among other uses, as an alternative to antiboitics for effective treatment of microbial infections.

\section{Conclusion}

Extracts of seeds of Mucuna pruriens have shown antimicrobial effects on some human pathogens.Also,despite the fact that most plant pathogens belong to the Gram negative bacteria,the extract proved more effective against Gram positive bacteria.However,this is a preliminary work and more works are neede to actually determine the active ingredients in this plant extracts.This can help in improving management of the different infectious diseases that are developing resistance to commonly used antiboitics.Furthermore,toxiclogical studies can also be carried out to determine the reliance on this herb without many side effects.

\section{References}

[1]. Aguiyi,j.c.,Johnson,P.B.,Obi,C.I.,Olorunfemi,P.D. and Adoga,G.(1996).Antimicrobial Activity and Preliminary Phytochemical Screening of Seeds of Mucuna pruriens.West Afr.J.Biol.Sci.5:71-76.

[2]. Baris,O.,Gulluce,M.,Sahin,F.,Ozer,H.,Kilic,H.,Ozakan,H.,Sokmen,M. and Ozbek,T.(2006).Biological Activities of the Essential Oil and Methanol Extract of Achilea biebersteinii Afam(Asteraceae).Turk.J.Biol.30:65-73.

[3]. Das,K.,Tiwari,R.K.S and Strivastava,D.K.(2010).Techniquesfor Evaluation of Medicinal Plant Products as Antimicrobial Agents:Current Methods and Future Trends.J.Med.Plants Research.4(2):104-111.

[4]. Devienne,K.F. and Raddi ,M.S.G.(2002).Screening for Antimicrobial Activity of Natural Products Using a Microplate Photometer.Braz.J.Microbilo.33(22):97-105.

[5]. Doughari,J.H.(2006).Antimicrobil Activity of Tamarndus indica Linn.Trop.J.Pharm.Res.592):597-603.

[6]. Esther,N.M. and Johannes,V.S.92003).Antibacterial Anti-inflammatory Activities osf Some Plants for Medicinal Purposes in Kenya.J.Ethroparmacol.87:35-41.

[7]. Geroge,T.,Frank,R.S.,Olga,L.,and Kim,L.(2002).Multidrug Pump Inhibitors Uncover Remarkable Activity of Plant Antimicrobials.J.Antimicrobial Activity of Essential Oil and Other plant Extracts.J.Appl.Microbiol.86(6):985-988.

[8]. Baris,D.F. and Fan,S.H.92005).The Potential of Aqueous and Extract of Galls of Quercus infectoria as Antibacterial Agent.Indian J.Pharmacol.37(1):26-29.

[9]. Hostettmann,K.(1999).Strategy for the Biological and Chemical Evaluation of Plant Extracts.Pure Appl.Chem.70(11):1-9.

[10]. Iwu,M.W.Ducan,A.R. and Okunji,C.O.(1999).New Antimicrobials of Plant Origin.Janick J.(ed):Perspective on New Uses,pp457462 .

[11]. Lewis ,K.W. and Elvin-Lewis,M.P.(1995).Medicinal Plants as Sources of New Therapeutics.Ann Mo.Bol.Gard.82:16-24.

[12]. Kianbakht,S and Jahaniani,F.(2003).Evaluation of Antimicrobial Activity of Tribulus terrestris Growing in Iran J.Pharmacol.Ther.2:22-24.

[13]. Ergene,A.,Guller,P.,Tan,S.,Mirici,S.Hamzoaglu,E.D.(2006).Antimicrobial and Antifungal Activity of Heracleum sphondylium Subsp.Artivinense.Afr.J.Biotectnol.5(11):1087-1089.

[14]. Munguti,K.(1997).Indegenous Knowledge in the Mangement of Malaria and Visceral Leishmaniasis Among the Tujen of Kenya.Indegen.Knowledge and Dev.Monitor.5:10-12.

[15]. Kokwaro,J.O.(1976).Medicinal Plants of East Africa.East Afr.Lit.Bureau.Nairobi.72:19-20.

[16]. Salie,F.,Eagles,P.F.K. and Lens,H.M.S.(1996).Preliminary Antimicrobial Screening of Four South African Asteraceace species.J.Ethnopharmacol.52(1):27-33.

[17]. Sindiga,I.(1991).Indegenous Medical Properties of Tannins.Phytochemistry.30:3875-3883.

[18]. Umeh,E.Oloma,H.O.A., and Igoli,O.(2005).Antibacterial Screening of Four Local Plants, Using an Indicator-basedMicrodilution Technique.Afr.J.Tradit.Complement.Altern.Med.2(3):238-243. 